\title{
Duas espécies novas de Dicranthidium Moure \& Urban (Hymenoptera, Megachilidae) e chave para a identificação das espécies ${ }^{1}$
}

\section{Danúncia Urban ${ }^{2}$}

\begin{abstract}
Two new species from Dicranthidium Moure \& Urban and a key to identify the species (Hymenoptera, Megachilidae). Dicranthidium aliceae sp. nov. from Santana do Riacho, Minas Gerais and Dicranthidium seabrai sp. nov. from Lençois, Bahia are described. A new key to the species of the genus is provided.

KEY WORDS. Hymenoptera, Megachilidae, Dianthidiini, Dicranthidium, taxonomy
\end{abstract}

O gênero Dicranthidium Moure \& Urban, 1975 é caracterizado pela carena pré-episternal longa e laminada, ausência das carenas genais e pré-occipital; o macho tem projeções laterais digitiformes no sétimo tergo e arólios e a fêmea tem quatro dentes mandibulares e somente a orbícula entre as garras, não tem arólios. URBAN (1992) incluiu D. arenarium (Ducke, 1907); D. colombiae (Schwarz, 1933); D. gregarium (Schrottky, 1905); D. insulare Urban, 1992; D. luciae Urban, 1992 e D. soniae Urban, 1992 em uma chave para a identificação das espécies. D. insulare é conhecida das Índias Ocidentais, TrINIDAD; D. colombiae de Magdalena e Boyaca, Colômbia; D. gregarium do Brasil, Paraíba até o Paraná, Mato Grosso e Goiás; PARAguai e Argentina: Tucumán, Salta, Formosa, Misiones e Mendoza. As outras espécies são conhecidas somente do BRASIL: D. arenarium do Maranhão até a Bahia; $D$. luciae do Ceará ao Rio de Janeiro e $D$. soniae do Rio de Janeiro ao Paraná. Neste trabalho são dadas a conhecer mais duas espécies, $D$. aliceae $\mathbf{s p . ~ n o v . ~}$ de Minas Gerais e D. seabrai sp. nov. da Bahia e uma nova chave é proposta para incluir as duas espécies novas, cujo material-tipo está depositado na Coleção de Entomologia Pe. J.S. Moure, Departamento de Zoologia, Universidade Federal do Paraná, Curitiba (DZUP).

\section{Dicranthidium aliceae sp. nov.}

Figs 1-3

Diagnose. Vértice com faixas laterais estreitas amarelas e máculas látero-basais amarelas no mesoscuto. Macho com genas pretas, projeções laterais do sétimo tergo mais longas que a metade do recorte entre as mesmas e duas fileiras de cerdas curtas e grossas nas coxas posteriores. Fêmea com faixas amarelas estreitas nas paroculares, primeiro, e do terceiro ao quinto tergo com nódoas amarelas aos lados, sexto tergo preto.

1) Contribuição número 1347 do Departamento de Zoologia, Universidade Federal do Paraná.

2) Departamento de Zoologia, Universidade Federal do Paraná. Caixa Postal 19020, 81531-980 Curitiba, Paraná, Brasil. Bolsista do CNPq. 
Holótipo macho. Comprimento total 7,49 mm (distendido); comprimento da asa anterior a partir do esclerito costal $5,38 \mathrm{~mm}$; largura da cabeça $2,23 \mathrm{~mm}$. Tegumento predominantemente preto. Cabeça com as seguintes áreas amarelas (Fig. 2): lado externo das mandíbulas, menos os dentes enegrecidos; clípeo, exceto pequenas máculas pretas triangulares junto à sutura epistomal; paroculares inferiores, a mácula amarela não chegando às suturas subantenais e muito estreita na altura dos alvéolos terminando pouco abaixo da tangente inferior ao ocelo mediano e ai mais ferrugínea; duas estrias interalveolares até a sutura epistomal. Vértice com faixas laterais ferrugíneas dos ocelos laterais ao topo dos olhos. Antenas com o escapo ventralmente amarelo, pedicelo e primeiros artículos ferrugíneos, demais artículos de um amarelo-ocre pálido porém passando a castanhos junto às articulações, a área castanha aumentando para os lados; dorsalmente ferrugíneo-acastanhados exceto o distal inteiramente preto. Mesoscuto com duas máculas basais amarelo-ferrugíneas, mais acastanhadas e menos conspícuas em direção aos flancos; escutelo e axilas com borda amarela; tégulas castanho-claras com mácula amarela anterior; asas tingidas com castanho-enegrecido; pernas com áreas amarelas, ferrugíneas e castanho-escuras; nas posteriores, os basitarsos e o primeiro tarsômero amarelos na face externa; fêmures anteriores e posteriores com estria amarela de contorno irregular. Tergos enegrecidos com larga margem translúcida castanho-clara, com as máculas amarelas assim distribuídas (Fig. 1): no basal duas grandes máculas laterais próximas do ápice do tergo nos lados e na parte mais dorsal próximas da base, alargadas no meio e afastadas por uma distância quase igual a duas vezes o comprimento do escapo; no segundo pequenas estrias látero-ventrais; terceiro com faixas laterais estreitas separadas por distância maior que o escapo e mais para o ápice nos flancos; quarto com as faixas laterais quase fundidas e quinto com faixa larga; sexto tergo amarelo com o preto da base prolongado medianamente em fina estria e sétimo amarelo com enegrecido na ponta das projeções digitiformes. Esternos de um amarelo ligeiramente acastanhado, os dois basais castanhos com máculas amarelas laterais.

Antenas com os flagelômeros crenulados, exceto os basais; sétimo tergo com projeções laterais digitiformes mais longas que a metade do recorte basal e com o ápice arredondado.

Variações. Um parátipo macho sem nódoas pretas no clípeo, outro com as estrias interalveolares unidas nas adjacências da sutura epistomal.

Alótipo fêmea. Comprimento total $6,39 \mathrm{~mm}$; comprimento da asa anterior a partir do esclerito costal $5,15 \mathrm{~mm}$; largura da cabeça $2,35 \mathrm{~mm}$. Tegumento preto exceto nódoas amarelas estreitas nas paroculares superiores, pouco menores que a metade do escapo e duas estrias laterais amarelo-ferrugíneas no vértice entre os ocelos laterais e o topo dos olhos (Fig. 3). Antenas mais escuras do que no macho, ferrugíneas ventralmente e castanhas na face dorsal. Mesoscuto com duas nódoas triangulares látero-basais amarelas; axilas com borda amarela e escutelo com pequenas áreas amarelas na margem; tégulas castanhas; asas tingidas com castanhoenegrecido (Fig. 3); coxas e trocanteres castanho-enegrecidos, fêmures e tarsos castanhos, tíbias anteriores e medianas com amarelo-ferrugíneo na face anterior. Tergos pretos; no primeiro duas máculas bem laterais e afastadas por uma distância 

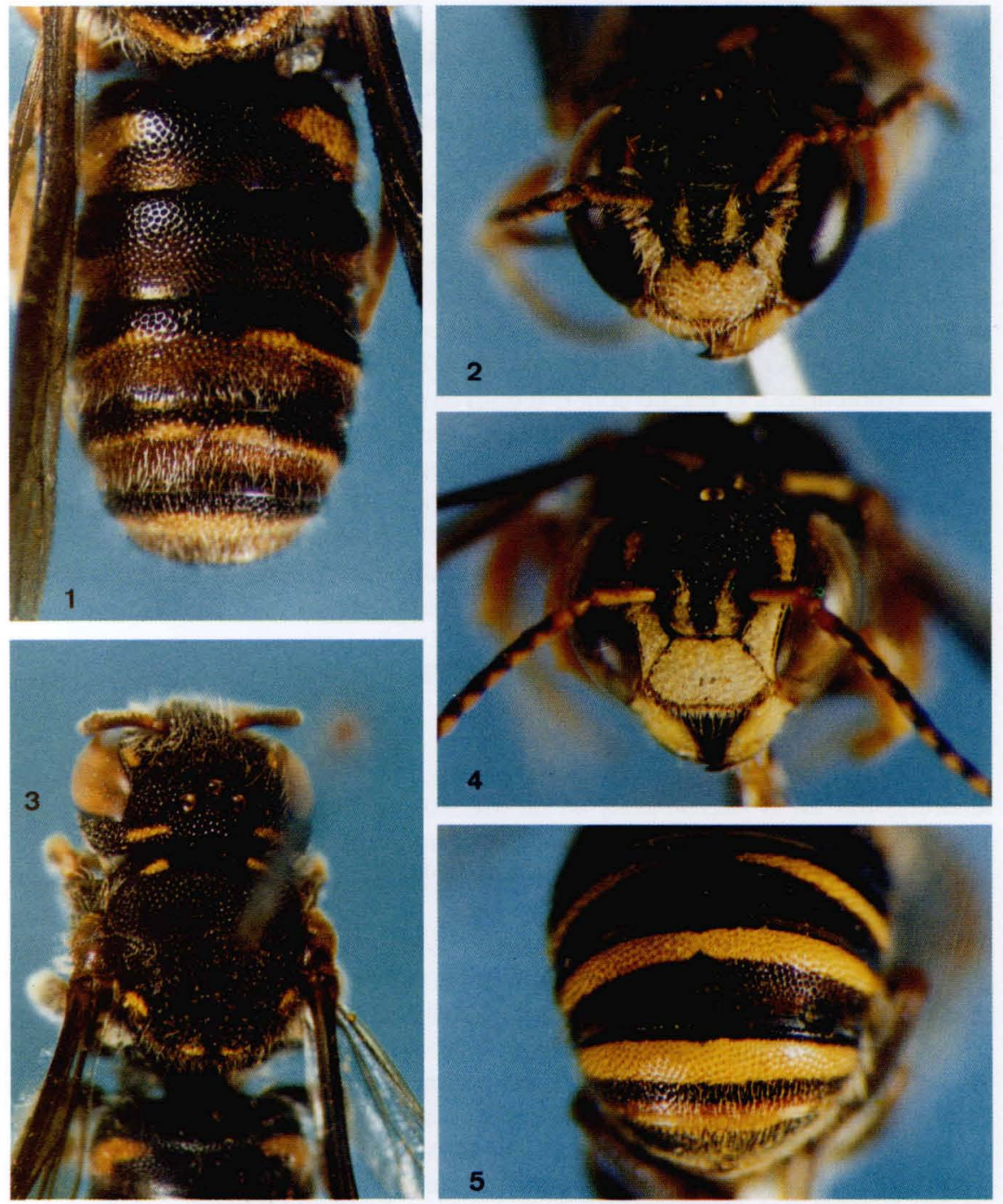

Figs 1-5. (1-3) Dicranthidium aliceae: (1-2) metasoma e cabeça do holótipo, (3) cabeça e mesosoma do alótipo fêmea; (4-5) Dicranthidium seabrai: (4) cabeça do holótipo, (5) tergos do alótipo.

igual e duas vezes o comprimento do escapo, nos flancos estreitas e perto da borda, largas no meio e a parte medial mais para a base do tergo e afilada; segundo tergo com pequenas faixas látero-ventrais amarelo-acastanhadas; terceiro com duas máculas basais retangulares mais largas que o diâmetro do ocelo e afastadas por distância igual ao dobro do ocelo; no quarto e quinto máculas laterais ovaladas separadas por espaço maior que o dobro do comprimento do escapo.

Revta bras. Zool. 19 (3): 637 - 643, 2002 
Variações nas fêmeas. Nos tergos dos parátipos coletados na mesma data, foi observada a redução no tamanho ou ausência das máculas no quarto e quinto tergos como também o seu escurecimento passando a mais ferrugíneas ou acastanhadas em vez de amarelas.

Holótipo macho. BRASIL, Minas Gerais: Santana do Riacho, Serra do Cipó, VIII.1961, F.M. Oliveira leg. Alótipo de Minas Gerais, Belo Horizonte, VIII.1961, F.M. Oliveira leg. Demais parátipos: um macho e uma fêmea com os mesmos dados do holótipo; 17 fêmeas e dois machos de Belo Horizonte com os mesmos dados do alótipo; duas fêmeas de Belo Horizonte, uma coletada em 10.XII.1998 e outra em 18.II.1999 por J.C. Moreira. Depositados no DZUP.

Comentário. O macho com o sétimo tergo como o de D. gregarium que se distingue de $D$. aliceae pela ornamentação ferrugínea nas paroculares superiores, vértice e genas, nestas, pelo menos no terço dorsal, e nos lados do mesoscuto com a forma de $\mathrm{L}$ invertido. A fêmea de $D$. aliceae distingue-se das demais espécies pelas faixas laterais ferrugíneas do vértice e estrias paroculares muito finas e curtas.

Etimologia. Homenagem à Profa. Dra. Alice Fumi Kumagai do Departamento de Zoologia da Universidade Federal de Minas Gerais.

\section{Dicranthidium seabrai sp. nov.}

\section{Figs 4-5}

Diagnose. Vértice com faixa ferrugínea; macho com genas pretas, máculas amarelas nas áreas látero-basais no mesoscuto, margem do escutelo e parte das axilas, sétimo tergo semelhante ao de $D$. aliceae. Fêmea com estria amarela muito curta e fina nas paroculares; mesoscuto e escutelo pretos; quarto ao sexto tergo com faixa amarela larga.

Holótipo macho. Comprimento total $6,24 \mathrm{~mm}$; comprimento da asa anterior a partir do esclerito costal $5,26 \mathrm{~mm}$; largura da cabeça $2,21 \mathrm{~mm}$. Tegumento preto com as seguintes áreas amarelas: face externa das mandíbulas e clípeo; áreas paroculares, a mácula muito estreita e com recorte arredondado pouco acima dos alvéolos, apicalmente arredondada; duas estrias interalveolares prolongadas até a sutura epistomal e ai unidas (Fig. 4); vértice com faixa ferrugínea. Antenas com o escapo amarelo ventralmente, pedicelo e demais flagelômeros de um amarelo-palha com castanho junto às articulações, dorsalmente tanto o escapo como os flagelômeros basais ferrugíneos, os intermediários castanhos e o distal inteiramente preto (Fig. 4). Mesoscuto com faixas látero-basais amarelas; tégulas castanhas com pequena área anterior amarelada; ponta ventral dos lobos pronotais, margem do escutelo e grande parte das axilas amarelos. Asas tingidas com castanho escuro. Pernas com áreas enegrecidas, ferrugíneas e amarelas, os fêmures com faixa amarela larga e os basitarsos com amarelo na face externa. Tergos castanho-enegrecidos com as manchas amarelas assim distribuídas: o basal com duas máculas grandes laterais separadas por distância igual a dois diâmetros de ocelo; o segundo com nódoas laterais muito pequenas; terceiro com faixas laterais estreitas, pouco alargadas dorsalmente; quarto e quinto tergos com faixa completa, sexto e sétimo com o amarelo predominando, a base do sexto e a ponta das projeções laterais do sétimo 
enegrecidas. Dois esternos basais castanho-enegrecidos, o segundo com máculas amarelas laterais, demais esternos amarelo-pálidos.

Antenas com os flagelômeros crenulados do quinto ao distal; sétimo tergo com as projeções digitiformes afiladas para a ponta e arredondadas no ápice.

Alótipo fêmea. Comprimento total $6,47 \mathrm{~mm}$; asa incompleta; largura da cabeça $2,47 \mathrm{~mm}$. Tegumento preto exceto finas estrias paroculares amarelas curtas, menores que o escapo; antenas ferrugíneas, os flagelômeros apicais tingidos com castanho; cantos das axilas com minúscula nódoa ferrugínea; tégulas castanhas; pernas castanhas com áreas castanho-ferrugíneas; dois tergos basais com pequenas nódoas amarelas bem laterais, terceiro com faixas laterais amarelas separadas por distância igual a dois diâmetros de ocelo; quarto e quinto tergos com faixa amarela discal larga; sexto amarelo na metade basal e preto na apical (Fig. 5).

Variações nas fêmeas. Dois parátipos de Viçosa com larga margem translúcida amarelo-ferrugínea no terceiro e quarto tergos, um deles também com nódoas amarelas minúsculas na base do mesoscuto; dois parátipos de Santa Leopoldina, um com a margem do quarto e quinto tergos translúcida e outro com as axilas amarelas quase por inteiro e sem estrias amarelas paroculares e sem margem translúcida amarelo-ferrugínea do terceiro ao quinto tergo.

Holótipo macho. BRASIL, Bahia, Lençois, 18.II.1988, nome do coletor ilegível. Alótipo fêmea do Rio de Janeiro: Rio de janeiro (Floresta da Tijuca), I.1956, C.A.C. Seabra leg. Parátipos: Espírito Santo, Santa Leopoldina, 3.IX.1964, uma fêmea e 4.III. 1964, uma fêmea, C. Elias leg.; Minas Gerais, Viçosa, 1.XII.1989, M. Thiengo leg., duas fêmeas. Depositados no DZUP.

Comentário. O macho com o sétimo tergo igual ao de $D$. gregarium, que se distingue de $D$. seabrai por ter máculas laterais ferrugíneas em $\mathrm{L}$ invertido no mesoscuto e as genas ferrugíneas por inteiro ou ao menos no terço dorsal. A fêmea tem em comum com $D$. soniae a faixa amarela larga nos três tergos distais, porém D. soniae tem a metade basal do clípeo amarela e máculas amarelas largas e bissinuosas nas paroculares.

Etimologia. Homenagem ao Dr. Carlos Alberto Campos Seabra, coletor de um dos exemplares.

\section{Chave para as espécies de Dicranthidium}

\section{Machos}

1. Coxas posteriores com numerosas cerdas grossas de ápice arredondado; sétimo tergo com depressões laterais no disco . . . . . . . . . . . . . . 2

1'. Coxas posteriores com uma cerda espiniforme grossa apical; sétimo tergo sem depressões laterais no disco ............. arenarium (Ducke, 1907)

2. Sétimo tergo com as projeções laterais espiniformes, mais curtas que a metade da distância entre as mesmas . .......................... 3

2'. Sétimo tergo com as projeções laterais digitiformes afinadas ou sub-truncadas na ponta, medindo aproximadamente $3 / 4$ da distância entre as mesmas ... 4 
3. Mesoscuto com máculas laterais amarelas em L invertido, a mácula até a sutura escuto-escutelar; fêmures posteriores com estria amarela da base ao ápice . luciae Urban, 1992

3'. Mesoscuto com faixas látero-basais amarelas, raramente com pequena expansão lateral; fêmures posteriores com nódoa amarela arredondada no ápice ..... . soniae Urban, 1992

4. Tergo basal com intervalos brilhantes entre os pontos, bordo liso desprovido de pontos; segundo tergo com máculas amarelas bem laterais, sem faixa completa; projeções digitiformes do sétimo tergo variáveis . . . . . . . . . 5

4'. Tergo basal com pontuação densa até o bordo, sem espaços brilhantes entre os pontos; segundo tergo com faixa amarela irregular; projeções digitiformes do sétimo tergo largas e truncadas na ponta .. . colombiae (Schwarz, 1933)

5. Projeções digitiformes do sétimo tergo muito finas na ponta, angulosas quando vistas de perfil; mesoscuto com máculas amarelas ou ferrugíneas variáveis .

5'. Projeções digitiformes do sétimo tergo com a ponta sub-truncada e larga, quando vistas de perfil sem aspecto anguloso, somente um pouco mais estreitas na ponta; mesoscuto com faixas látero-basais amarelas .. insulare Urban, 1992

6. Vértice com faixa amarela ou ferrugínea; mesoscuto com máculas variáveis . . 7

6'. Vértice com estrias laterais ferrugíneas; mesoscuto com faixas látero-basais amarelas ...................................

7. Genas inteiramente ferrugíneas ou pelo menos no terço dorsal; mesoscuto com máculas laterais ferrugíneas em L invertido ..... gregarium (Schrottky, 1905)

7'. Genas pretas; mesoscuto com faixas látero-basais amarelas ... seabrai sp. nov.

\section{Fêmeas}

1. Cabeça com predominância do preto ou ferrugíneo, quando em grande parte amarela com área supraclipeal preta; disco do mesoscuto e do escutelo com os intervalos brilhantes entre os pontos ................... 2

1'. Cabeça predominantemente amarela com as mandíbulas, fronte e área ocelar pretas; disco do mesoscuto e do escutelo sem brilho, com pontos e intervalos foscos . . . . . . . . . . . . . . . . . . colombiae (Schwarz, 1933)

2. Mesoscuto com máculas laterais amarelas ou ferrugíneas em L invertido até a sutura escuto-escutelar .......................... 3

2'. Mesoscuto com máculas látero-basais amarelas ou ferrugíneas, às vezes com pequena expansão lateral curta ....................... 5

3. Terceiro ao quinto tergo sem faixa discal completa, com faixas laterais ou nódoas amarelas ................................ 4

3'. Terceiro ao quinto tergo com faixa discal amarela . . . . . insulare Urban, 1992

4. Cabeça e dorso do mesosoma com máculas ferrugíneas; fêmures sem estria amarela ao longo do comprimento .......... gregarium (Schrottky, 1905) 
4'. Cabeça e dorso do mesosoma com máculas amarelas ou amarelo-esbranquiçadas; fêmures com estria amarela ao longo do comprimento . . . . . . . . . . . luciae Urban, 1992

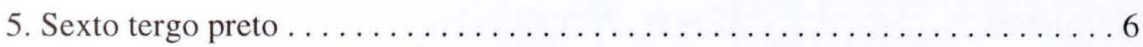

5'. Sexto tergo em grande parte amarelo . . . . . . . . . . . . . . . 7

6. Vértice com faixa amarela, paroculares com mácula amarela larga e bissinuada; fêmures com estria amarela . . . . . . . . . . arenarium (Ducke, 1907)

6'. Vértice com estrias laterais amarelo-ferrugíneas, paroculares com estrias amarelas curtas e delgadas; fêmures pretos, sem desenhos claros . . . . . . . . . $\ldots \ldots \ldots \ldots \ldots \ldots \ldots \ldots \ldots \ldots \ldots \ldots \ldots \ldots \ldots \ldots \ldots \ldots \ldots \ldots \ldots$ alicea $\mathbf{s p .}$ nov.

7. Clípeo preto; paroculares pretas ou com pequena estria amarela . . . . . . . . . seabrai sp. nov.

7'. Metade basal do clípeo amarela; paroculares com larga mácula amarela bissinuosa . . . . . . . . . . . . . . . . . . . . . . soniae Urban, 1992

AGRADECIMENTOS. Ao Prof. Dr. Albino Morimasa Sakakibara pelas fotos que ilustram o trabalho.

\section{REFERÊNCIA BIBLIOGRÁFICA}

URBan, D. 1992. Considerações sobre Anthidulum Michener, stat. n. e Dicranthidium Moure \& Urban, stat. n. e descrições de espécies novas (Hymenoptera, Megachilidae). Revta bras. Zool. 9 (1/2): 11-28.

Recebido em 13.III.2002; aceito em 11.VII.2002. 
